\title{
The Importance and Applications of Knoevenagel Reaction (Brief Review)
}

\section{RICHA KHARE*, J. PANDEY, SMRITI and RUCHI RUPANWAR}

Amity University, Uttar Pradesh, Lucknow Campus, Lucknow-226028, India.

${ }^{*}$ Corresponding author E-mail: rkhare @ lko.amity.edu

http://dx.doi.org/10.13005/ojc/350154

(Received: November 13, 2018; Accepted: December 01, 2018)

\section{ABSTRACT}

Knoevenagel reaction is one of the classical ways of $\mathrm{C}=\mathrm{C}$ bond formation where a carbon nucleophile is added to a carbonyl function followed by a dehydration. This name reaction has a great reputation in synthetic organic chemistry by virtue of its application in the synthesis of molecules of varied interest. Here in, the importance and supplication of Knoevenagel reaction are reviewed.

Keywords: Knoevenagel reaction, Carbon nucleophile.

\section{INTRODUCTION}

In organic chemistry, the Knoevenagel reaction is widely used for $\mathrm{C}=\mathrm{C}$ bond formation ${ }^{1,2}$. The product obtain is $\alpha, \beta$-unsaturated compound which is mostly used as intermediate in the formation of natural products ${ }^{4}$, therapeutic agents ${ }^{3}$, adequate chemicals ${ }^{6}$, polymers having different functional groups $^{5}$, insecticides and pesticides. It is usually carried out in organic solvents and catalyzed by organic bases such as pyridine or piperidine ${ }^{2}$. The use of this reaction limits in industrial process as they are associated with dangerous and carcinogenic solvents and sometime non-recoverability of the catalysts.

lonic liquid have gained importance over the past more than a decade. This is by virtue of various intrinsic properties e.g. no vapor pressure, wide range of high temperature tolerance etc ${ }^{7}$. Ionic liquids are considered green and ecofriendly ${ }^{8}$. Ionic liquids in Knoevenagel reaction as solvents/or catalyst which often found to accelerate the reaction has attributed considerable success ${ }^{9-11}$ in the area of condensation, easy work-up, and easy recyclability ${ }^{12-14}$. This reaction is named after Emil Knoevenagel in 1890. This is modification of Aldol condensation in which an enol react with carbonyl compound to form a conjugated enone ${ }^{15}$.

\section{Chemistry}

The Knoevenagel reaction is based on nucleophilic addition, in which active hydrogen compound added to the carbonyl compound followed by the removal of water. The product obtain is $\alpha, \beta$-unsaturated ketone ${ }^{15}$.

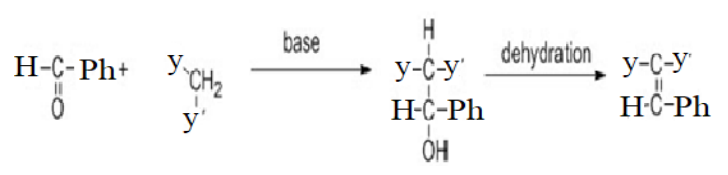

Scheme 1. Knoevenagel Reaction ${ }^{16}$

This is an Open Access article licensed under a Creative Commons license: Attribution 4.0 International (CC- BY). Published by Oriental Scientific Publishing Company @ 2018 
Where $y, y^{\prime}$ (electron withdrawing groups) $=\mathrm{CO} 2 \mathrm{R}, \mathrm{COR}, \mathrm{CHO}, \mathrm{CN}, \mathrm{NO} 2$, etc .

\section{Mechanism}
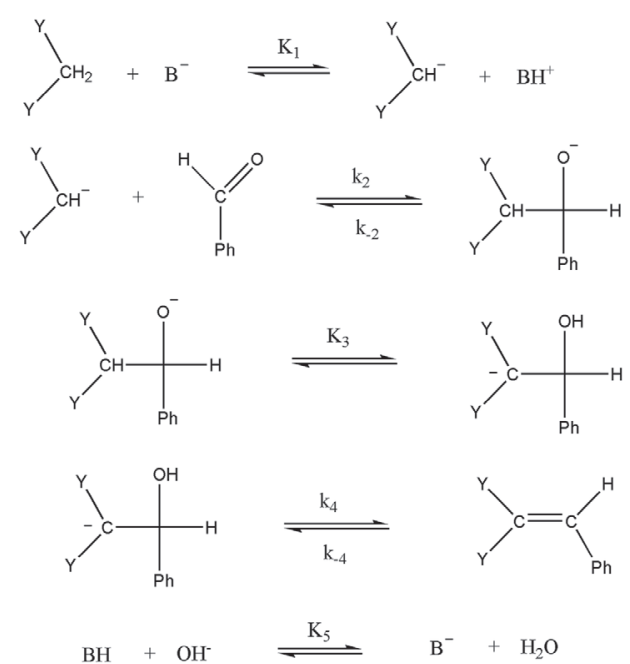

Scheme 2. Mechanism of Knoevenagel reaction ${ }^{16}$

Firstly, a base abstract a proton from alkane and forms carbanion. Carbanion acts as a nucleophile which attack on the carbonyl group i.e. aldehyde group followed by addition. Then the rearrangement take place within the molecule which again form carbanion. Hydroxide ion abstract another proton and formed a double bond resulting in the formation of alkene. $\mathrm{K}_{1}, \mathrm{~K}_{2}, \mathrm{~K}_{3}, \mathrm{~K}_{4}, \mathrm{~K}_{5}$ are the reaction constant. $\mathrm{K}_{2}$ is the slow step and also rate determining step.

\section{Doebner Modification}

This is the modification of Knoevenagel reaction. In this malonic compounds are used in reaction to obtain a molecule by losing carbon dioxide in subsequent step. For example, reaction of aldehyde with malonic acid in presence of pyridinegive trans-2, 4-Pentadienoic acid ${ }^{27}$.

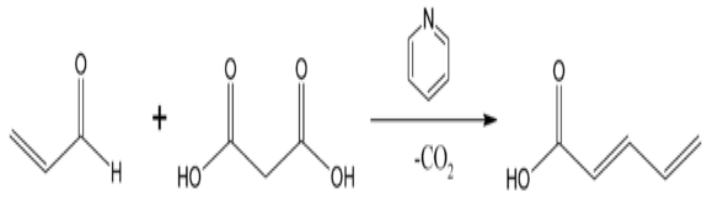

Scheme 3. Reaction of Aldehyde \&Malonic acid²7

\section{Reactions}

S. Fioravanti, L. Pellacani, P. A. Tardella, M. C. Vergari discussed that the reaction of aliphatic aldehyde with nitro alkane in the presence of a catalyst like piperdine is quite efficient. Simply by changing the reaction condition and it is possible to control the stereo chemical outcomes of reaction by producing pure $(E)$ and (Z)-nitro alkenes in high yield ${ }^{17}$.

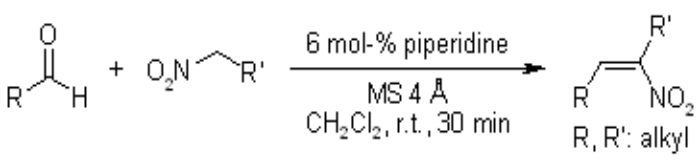

Scheme 4. Reaction of Aldehyde \& Nitro alkane ${ }^{17}$

J. S. Yadav, B. S. S. Reddy, A. K. Basak, B. Visali, A. V. Narsaiah, K. Nagaiah discussed that Triphenylphosphine was used as a catalyst to obtain olefin by treating aldehyde with malononitrile or cyanoacetate ${ }^{18}$.

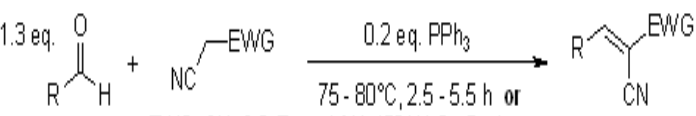

$$
\begin{aligned}
& \text { EWG: } \mathrm{CN}_{1} \mathrm{CO}_{2} \mathrm{Et} \quad \mathrm{MW}, 450 \mathrm{~W}, 2.5 \mathrm{~min}
\end{aligned}
$$

Scheme 5. Reaction of Aldehyde \&Malononitrile ${ }^{18}$

K. Ebitani, K. Motokura, K. Mori, T. Mizugaki, K. Kaneda used hydrotalcites as a catalyst in water which is followed by Knoevenagel reaction ${ }^{19}$.

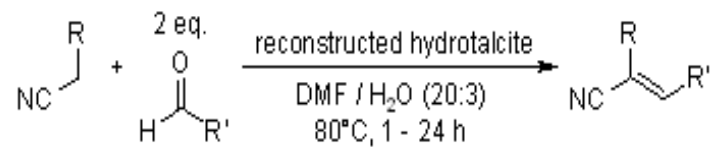

Scheme 6. Reaction of Aldehyde \& Alkyl Cyanide ${ }^{19}$

Y. Ogiwara, K. Takahashi, T. Kitazawa, N. Sakaiused Indium (III) Chloride as a catalyst in reaction of acetic anhydride and aldehyde which is followed by Knoevenagel reaction ${ }^{20}$.

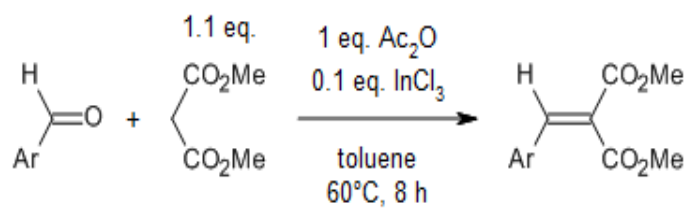

Scheme 7. Reaction of Aldehyde \& Acetic Anhydride ${ }^{20}$

Ce Su, Zhen-Chu Chen*, Qin-GuoZheng reported that the 1-butyl-3-methylimidazonium tetrafluoroborate [bmim] $\mathrm{BF}_{4}$ can be used for ethylenediammoniumdiacetate (EDDA)-catalyzed Knoevenagel reaction between aldehyde and active methylene compound ${ }^{21}$.

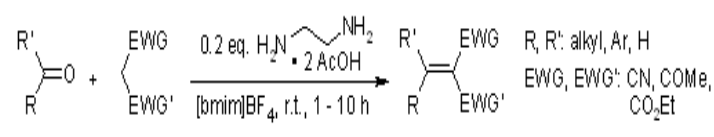

Scheme 8. Reaction of Aldehyde \& active methylene compound ${ }^{21}$ 
Brindaban C. Ranu*, Ranjan Jana used the basic ionic liquid1-butyl-3-methylimidazolium hydroxide, [bmlm] OH to catalyze the Knoevenagel reaction between aldehyde and active methylene group ${ }^{22}$.

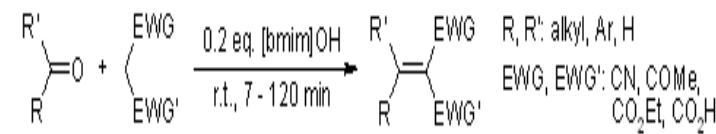

Scheme 9. Reaction of Aldehyde \& active methylene

N. Mase, T. Horibe suggested that carbamic acid ammonium salt used as an organocatalyst give the desired Knoevenagel reaction between aldehyde and active methylene group and give $98 \%$ yield $^{23}$.

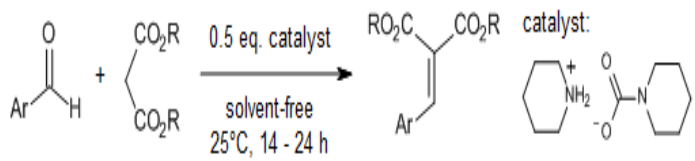

Scheme 10. Reaction of Aldehyde \& active methylene compound $^{23}$

J. K. Augustine, Y. A. Naik, A. B. Mandal, N. Chowdappa, V. B. Praveen have successfully employed gem-dibromomethylarenes for the synthesis for $\alpha, \beta$-unsaturated carboxylic acid ${ }^{24}$.

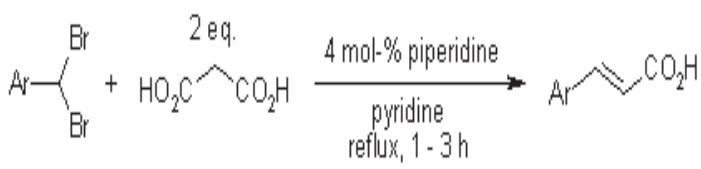

Scheme 11. Reaction of gem-dibromomethylarenes\& Active Methylene compound ${ }^{24}$

Jinni Lu, Patrick H. Toy employed bifunctional polystyrene bearing both DMAP and piperidine in Knoevenagel reaction to give E-cinnamates in high yields by reaction of aryl aldehyde and monoethylmalonate ${ }^{25}$.

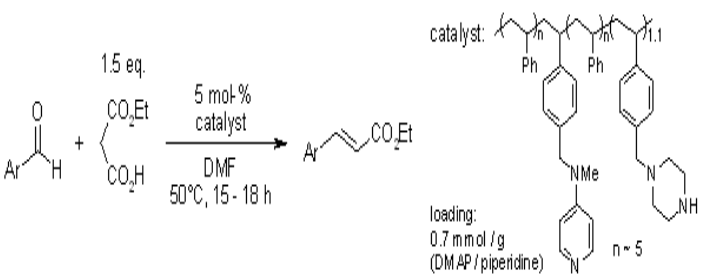

Scheme 12. Reaction of aryl aldehyde \& monoethylmalonate ${ }^{25}$

Amar R. Mohite and Ramakrishna G. Bhat used $\mathrm{FeCl}_{3}$ as a catalyst in water during decarboxylation of methylene tethered cyclic 1,3 -diesters to obtain $\alpha, \beta$-unsaturated carboxylic acid ${ }^{26}$.

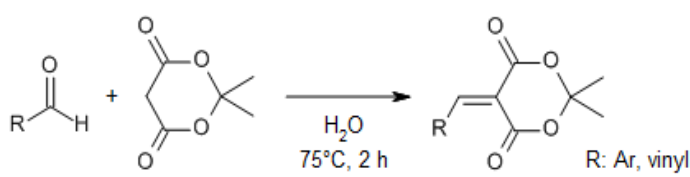

Scheme 13. Reaction of Aldehyde \& Acetic Anhydride ${ }^{26}$

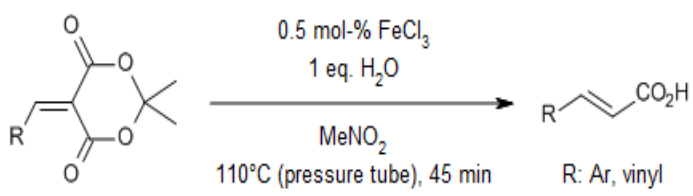

Scheme 14. Decarboxylation of methylene tethered cyclic 1, 3-diester ${ }^{26}$

\section{Catalytic Reduction of Chromenes}

It is a substance, ions, molecules which take part in chemical reaction which alters the rate of a chemical reaction without being used up in the reaction. It is required in small amount ${ }^{28}$.

In the presence of catalyst reaction occur faster as they require less activation energy. They formed intermediate which regenerates the original catalyst in cyclic process.

Catalyst may be categorized as homogeneous or heterogeneous ${ }^{28}$. Homogeneous catalyst molecule dispersed in same phase as the reactant molecule while in heterogeneous catalyst one molecule are not in same phase as reactant.

Less energy is required to attain the transition state by using catalyst. Catalyst are not being used up by the reaction but may get inhibited, destroyed, or deactivated. It is work by giving an alternative path to the reaction. As the alternative path have less energy, the rate of the reaction has increased.

\section{Heterogeneous catalysts}

They are used in different phase than the reacting species. Mostly, they are solids and act on substrate in a liquid or gaseous reaction mixture. Surface area of solid substrate really matter. As the surface area increases, the rate of the reaction also increases $^{29}$.

They have active sites where the reaction actually take place. For example, in the Haber process, iron acts as a catalyst for synthesis of ammonia from nitrogen and hydrogen. 


\section{Homogeneous catalysts}

They are used in same phase as in the reacting species. They are generally used by dissolving in the solvents with the substrate ${ }^{30}$. For example, influence of $\mathrm{H}^{+}$in the formation of methyl acetate from acetic acid and methano ${ }^{30}$.

\section{Reduction}

It is defined as the addition of hydrogen atom or removal of oxygen atom. It is also defined as gaining of electrons by one of the atom involved in the reaction ${ }^{31}$. For example, hydrogen chloride is obtain by reaction of hydrogen and chlorine. In this chlorine gas is reduced.

$\mathrm{Cl}_{2}+\mathrm{H}_{2} \rightarrow 2 \mathrm{HCl}$

In the same way, hydrogen is added to chlorine to obtain hydrogen sulphide, by reducing chlorine.

$\mathrm{H}_{2} \mathrm{~S}+\mathrm{Cl}_{2} \rightarrow 2 \mathrm{HCl}+\mathrm{S}$

\section{Catalytic Reduction}

It is defined as the reduction which take place in the presence of catalyst. For example, reduction of nitro phenol to amino phenol by borohydride is the catalytic reduction. In this we use Au nanoparticle as a catalyst and Sodium Borohydride $\left(\mathrm{NaBH}_{4}\right)$ as a reducing agent ${ }^{32}$.

$$
\mathrm{HO}-\mathrm{NO}_{2} \frac{\begin{array}{l}
\mathrm{Au} / \mathrm{PMMA}^{2} \\
\text { excess } \mathrm{NaBH}_{4}
\end{array}}{\mathrm{H}_{2} \mathrm{O}} \rightarrow \mathrm{HO} \longrightarrow \mathrm{NH}_{2}
$$

Scheme 15. Reduction of Nitro Phenol ${ }^{32}$

\section{Chromenes}

Chromene is the IUPAC nomenclature of benzopyran. Benzopyran is an organic compound having heterocyclic pyran ring fused with benzene ring. It have two isomers that vary by the fusion of two rings followed by oxygen atom, 1 - benzopyran (chromene) and 2-benzopyran (isochromene) ${ }^{33}$.

Benzopyran is paramagnetic in nature due to unpaired electron which delocalized over the ring. Due to this it become less reactive ${ }^{33}$.

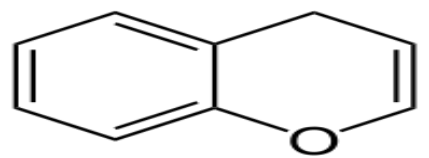

Scheme 16. Benzopyran ${ }^{33}$<smiles>C1=Cc2ccccc2CO1</smiles>

$1 \mathrm{H}$-Isochromene<smiles>C1=c2ccccc2=COC1</smiles>

$3 \mathrm{H}$ - Isochromene
Scheme 17. Structural isomers of chromene

\section{Substituted Chromene}

Chromene which have substitution on their ring rings by the replacement of hydrogen atom $^{33}$. For example, 2-Amino-3-cyano-7-hydroxy4Hchromenes.<smiles>N#CC1=C(N)Oc2cc(O)ccc2C1c1ccccc1</smiles>

Scheme 18. 2-Amino-3-cyano-7-hydroxy-4Hchromenes ${ }^{33}$

\section{Synthesis of Substituted Chromenes}

1. Behbahani, Farahnaz K. and Mehraban, Sima used L-proline as a biocatalyst for synthesizing 2-Amino-3-cyano-7-hydroxy-4Hchromenes by reacting Benzaldehyde\&malonotrile with resorcino ${ }^{34}$.

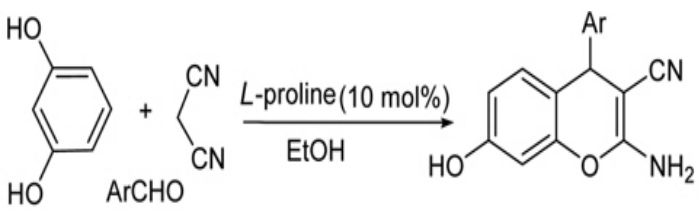

Scheme 19. Reaction of Benzaldehyde \& malonotrile with resorcinol ${ }^{34}$

Sandeep R. Khale, Manoj B. Gawande used $\mathrm{Mg} / \mathrm{Al}-\mathrm{HT}$ catalyst for synthesizing 2-Amino-3-cyano7-hydroxy-4-(3-chloro)-4Hchromene by reaction of malononitrile, aldehyde and resorcinol ${ }^{35}$.

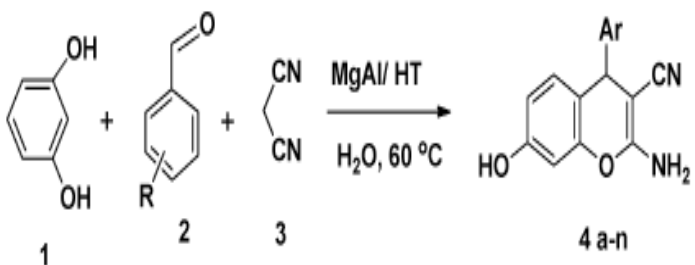

$\mathrm{R}=\mathrm{H}, 2-\mathrm{Cl}, 3-\mathrm{Cl}, 4-\mathrm{Cl}, 4-\mathrm{NO}_{2}, 3-\mathrm{NO}_{2}$, 2-thiophene, $4-\mathrm{Me}, 4-\mathrm{OMe}, 4-\mathrm{OH}, 2,5-(\mathrm{OMe})_{2}, 3,4-(\mathrm{OMe})_{2}, 4-\mathrm{F}, 4-\mathrm{Br}$

Scheme 20. Synthesis of Chromene ${ }^{35}$ 
Masesane, Ishmael B. and Mihigo, Shetonde O. used sodium carbonate as a catalyst for synthesizing 2-Amino-4H-chromenes using malononitrile, benzaldehydes, and phloroglucinol or resorcinol in water ${ }^{36}$.

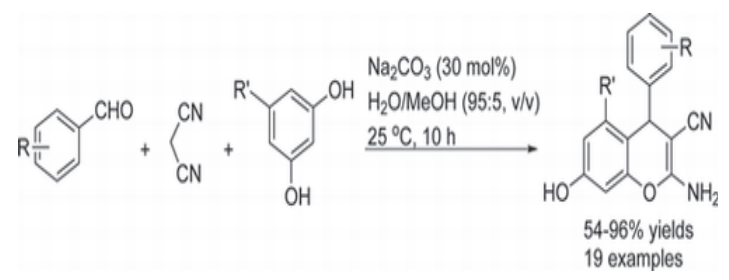

Scheme 21. Synthesis of 2-Amino-4H-chromenes ${ }^{36}$

Pourmohammad, Maryam and Mokhtary, Masoud used potassium carbonate as a catalyst for synthesizing 2-Amino-4H-chromenes using malononitrile, benzaldehydes, or resorcinol ${ }^{37}$.

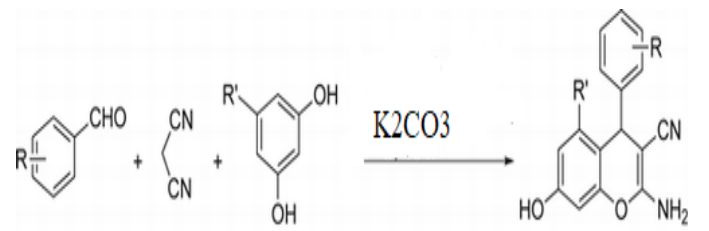

Scheme 22. Synthesis of 2-Amino-3-Cyano-4H-Chromene by $\mathrm{K}_{2} \mathrm{CO}_{3}{ }^{37}$

Mobinikhaledi, Akbar used triethyl amine as a catalyst for synthesizing 2-Amino-4Hchromenes using malononitrile, benzaldehydes, or resorcinol ${ }^{38}$.

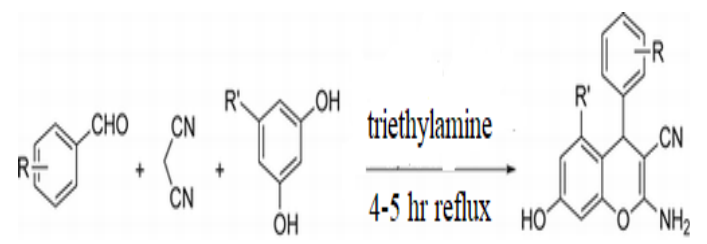

Scheme 23. Synthesis of 2-Amino-3-Cyano-4H-Chromene by triethyl amine ${ }^{38}$

Kundu, SudiptaK.used the TAFMC-1 as a catalyst for synthesizing 2-Amino-4H-chromenes using malononitrile, benzaldehydes, or resorcinol ${ }^{39}$.

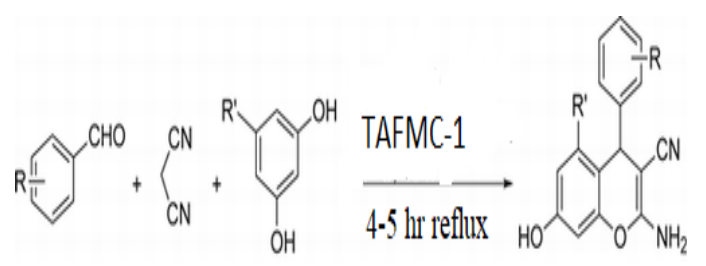

Scheme 24. Synthesis of 2-Amino-3-Cyano-4H-Chromene by TAFMC $-1^{39}$
Javad Safari 1 , ZohreZarnegar 1 , Marzieh Heydarian have found $\mathrm{Fe}_{3} \mathrm{O}_{4}$ Nanoparticles as efficient and Reusable Catalyst for synthesizing 2-Amino-4H-chromenes using malononitrile, benzaldehydes, or resorcinol ${ }^{40}$.

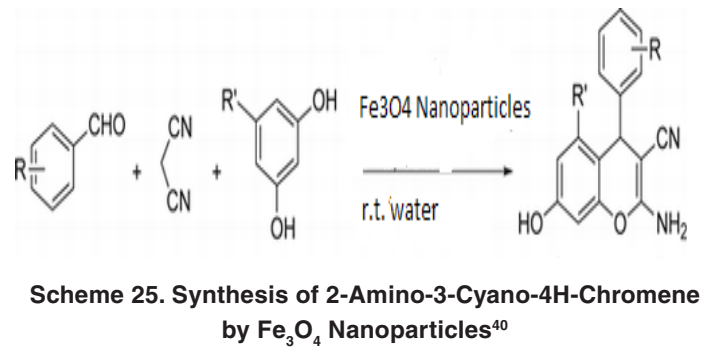

Mohammad G. Dekamin*, Mohammad Eslami, Ali Maleki used potassium phthalimide-Noxyl (POPINO) as catalyst for synthesizing 2-Amino$4 \mathrm{H}$-chromenes using malononitrile, benzaldehydes, or resorcinol ${ }^{41}$.<smiles>[R]c1cc(O)cc(O)c1</smiles>

Scheme 26. Synthesis of 2-Amino-3-Cyano-4H-Chromene by (POPINO) ${ }^{41}$

Bandita Datta, M.A. Pasha used glycine as catalyst for synthesizing 2-Amino-4H-chromenes using malononitrile, benzaldehydes, or resorcinol under sonic condition ${ }^{42}$.<smiles>[R]c1cccc(C=O)c1</smiles>

Scheme 27. Synthesis of 2-amino-4H-chromenes by using glycine as catalyst ${ }^{42}$

Dushyant Singh Raghuvanshi and Krishna Nand Singh have successfully employed MW irradiation in the presence of DBU (5 mol\%) in ethanol at an ambient temperature $50^{\circ} \mathrm{C}$ for synthesis of 2-Amino-3-cyano-4H-chromene ${ }^{43}$. 


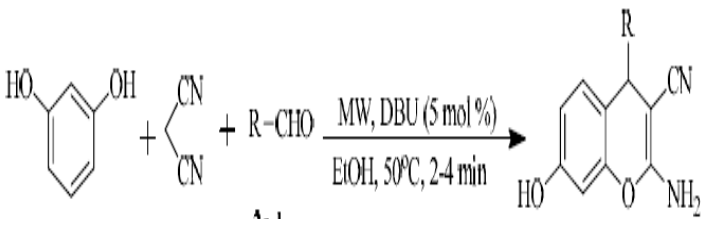

Scheme 28. Synthesis of 2-amino-4H-chromenes by using DBU as catalyst ${ }^{43}$

\section{RESULT \& DISCUSSION}

\section{Result}

Catalytic reduction of chromene under hydrogenation in autoclave afforded chromans. These resultans are the class of benzopyran derivatives frequently found in biologically active natural products such as vitamin $\mathrm{E}$ or flavonol. Chroman derivatives have been found to showt a variety of activities, including antioxidant or antibacterial properties.

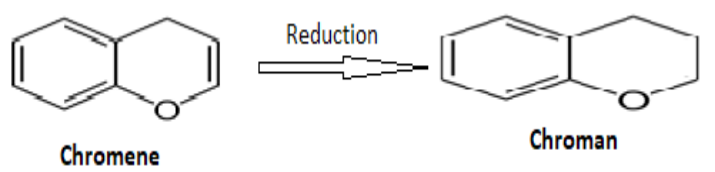

Scheme 29: Reduction of Chromene

\section{CONCLUSION}

There were various methods employed towards the synthesis of $4 \mathrm{H}$-chromenes particularly substituted at $3^{\text {rd }}$ and $4^{\text {rth }}$ positions. In one of the methods developed by us, aqueous sodium carbonate has preferably been used to prepare $4 \mathrm{H}$-chromene derivatives. Moreover, our studies have been found to show that by adopting this method we should be able to synthesize library of compounds of medicinal significance. Series of useful compounds have been accessed by using $3 \& 4$ hydroxybenzaldehyde and malononitrile. One of the goals to develop this synthetic strategy is to accommodate sterically hindered starting materials during the condensation events. It has been found that sterically hindered carbonyls are less likely to take part in condensation with malanonitrile through a traditional protocol. This has been observed in traditional methods as the side products are major ones that have been isolated. Eventually, our method has allowed us to make diversified molecules that would potentially exhibit promising biological activities. On-going efforts are to optimize reaction conditions in such a way that it can serve as a guiding principal to devise synthetic routes for accessing diversified molecules of various biological significance. The molecules prepared demonstrate the ability of the methods to afford compounds with various pharmacophores.

\section{Future Aspects}

Methods for various transformations should be developed in way that there is robustness inbuilt towards accommodating various substrates during transformation with slight changes in reactions conditions. Substituted chromenens which we synthesized have high yield and can easily be prepared. They have anti-bacterial and antifungal activity. They can be used as anticancer drug when reduced to chroman. In future they can be used as anti-bacterial, anti-fungal and anti-cancer drug as they have less side effect and are more effective at small quantity.

\section{ACKNOWLEDGEMENT}

J.P and R.K are thankful to DST for financial support (Grant registration\#CS-236/2013). J.P and R.K are also thankful to UPCST (Grant registration \# CST/ D 6547/2017).

\section{REFERENCES}

1. Freeman, F., Chem. Rev., 1980, 80, 329-350.

2. Tietze, L.F., Chem. Rev., 1996, 96, 115-136.

3. Kraus, G.A.; Krolski, M. E., J. Org. Chem. 1986, 51, 3347-3350.

4. Tietze, L.F.; Rackelmann, N., Pure Appl. Chem. 2004, 76, 1967-1983.

5. Liang, F.-J.; Pu, Y.; Kurata, T.; Kido, Liang, F.-J.; Pu, Y.; Kurata, T.; Kido, J.; Nishide, $\mathrm{H}$. Polymer., 2005, 46, 3767.

6. Zahouily, M.; Salah, M.; Bahlaouane, B.;
Rayadh, A.; Houmam, A.; Hamed, E.A.; Sebti, S. Tetrahedron., 2004, 60, 1631-1635.

7. Poole, C.F. J. Chromatog. A., 2004, 1037, 49-82.

8. Welton, T.; Wasserscheid, P., 2003, 1, 37-41.

9. Zhang, J.; Jiang, T.; Han, B.; Zhu, A.; Ma, X. Chem. Res. Chinese U., 2006, 36, 33053317.

10. Xin, X.; Guo, X.; Duan, H.; Lin, Y.; Sun, H. Chem. Res. Chinese U., 2007, 8, 115-117. 
11. Gao, G.; Lu, L.; Zou, T.; Gao, J.; Liu, Y.; He, M. Chem. Res. Chinese U., 2007, 23, 169-172.

12. Yue, C.; Mao, A.; Wei, Y.; Lü, M. Catal. Commun., 2008, 9, 1571-1574.

13. Wang, W.; Cheng, W; Shao, L.; Liu, C.; Yang, J. H. Kinet. Catal., 2009, 50, 186-191.

14. Xu, D.-Z.; Liu, Y.; Shi, S.; Wang, Y. Green Chem., 2010, 12, 514-517.

15. Knoevenagel, E. Berichte der deutschen chemischenGesellschaft., 1898, 31(3), 2596-2619.

16. March, J. In Advanced Organic Chemistry: Reactions, Mechanisms, and Structure, McGraw-Hill., 1968, 693, 697-698.

17. Fioravanti S.; Pellacani, L.; Tardella P. A.; Vergari M. C. Org. Lett., 2008, 10(7), 1449-1451.

18. Yadav, J. S.; Reddy, B. S. S.; Basak, A. K.; Visali, B.; Narsaiah, A. V.; Nagaiah, K. Eur. J. Org. Chem., 2004, 546-551.

19. Ebitani, K.; Motokura, K.; Mori, K.; Mizugaki, T.; Kaneda, K. J. Org. Chem., 2006, 71, 5440-5447.

20. Ogiwara, Y.; Takahashi, K.; Kitazawa, T.; Sakai N. J. Org. Chem., 2015, 80, 3101-3110.

21. Su, C.; Chen, Z-C.; Zhen, Q.-G. "The ionic liquid 1-butyl-3-methylimidazonium tetrafluoroborate [bmim]BF4 was used for ethylenediammoniumdiacetate (EDDA)catalyzed Knoevenagel condensation between aldehydes or ketones with active methylene compounds "Synthesis., 2003, 555-559.

22. Ranu, B. C.; Jana, R. Eur. J. Org. Chem., 2006, 3767-3770.

23. Mase, N.; Horibe, T. Org. Lett., 2013, 15(8), 1854-1857.

24. Augustine, J. K.; Naik, Y. A.; Mandal, A. B.; Chowdappa, N.; Praveen, V. B. J. Org. Chem., 2007, 72(25), 9854-9856.

25. Lu. J.; Toy. P. H. Synlett., 2011, 1723-1726.

26. Mohite, A. R.; Bhat, R. G. Org. Lett., 2013, 15, 4564-4567.
27. Doebnerun, O. Gesättigten Säuren.,1902, 1136-38.

28. 7 things you may not know about catalysis Louise Lerner, Argonne National Laboratory available at http://www.anl.gov/articles/ 7-things-you-may-not-know-about-catalysis (03/06/2017)., 2011.

29. Knözinger, K. H.; K. Kochloefl. Wiley-VCH, Weinheim., 2002, 5, 313.

30. Behr, A. Wiley-VCH., 2002, 18, 215.

31. Oxidation and Reduction, Khan Academy, retrieved, Available athttps://www.khanacademy. org/science/chemistry/oxidation-reduction/ redox-oxidation-reduction/v/introduction-tooxidation-and-reduction., 2017.

32. Kyoko, K.; Tamaolshidaa. Journal of Molecular Catalysis A: Chemical., 2009, 298(1-2), 7-11.

33. Nomenclature of Organic Chemistry: IUPAC Recommendations and Preferred Names 2013 (Blue Book). Cambridge: The Royal Society of Chemistry., 2014, 211-214.

34. Behbahani, F. K.; MehrabanSima. Journal of the Korean Chemical Society., 2015, 59(4), 284-288.

35. Pourmohammad, M.; Mokhtary, M. Comptes Rendus Chimie., 2015, 18(5), 554-557.

36. Akbar $\mathrm{M}^{*}$.; Naser, F.; Tahere, M.; Ahmad, H. Iranian Journal Of pharmaceutical Research., 2014, 13(3), 873-879.

37. Kundu.; Sudipta K. Dalton Transactions., 2013, 42(29), 10515-10524.

38. Javad. S.; Zohre, Z.; Marzieh, H. Bulletin of the Chemical Society of Japan., 2012, 85(12), 1332-1338.

39. Mohammad G. D*.; Mohammad. E.; Ali. M. Tetrahedron., 2013, 69(3), 1074-1085.

40. Bandita.D.; Pasha. M.A. Ultrasonics Sonochemistry., 2012, 19(4), 725-728.

41. Raghuvanshi. D.S.; Singh. K. N. ,ARKIVOC (Gainesville, FL, United States), 2010, 10, 305-317. 